Article type: Original Article

\title{
Holocene range collapse of giant muntjacs and pseudo- endemism in the Annamite large mammal fauna
}

Samuel T. Turvey ${ }^{1}$, James Hansford ${ }^{1,2}$, Selina Brace ${ }^{3}$, Victoria Mullin ${ }^{4}$, Shengxiao $\mathrm{Gu}^{5}$ and Guoping Sun 6

${ }^{1}$ Institute of Zoology, Zoological Society of London, Regent's Park, London NW1 4RY, UK

${ }^{2}$ School of Ocean and Earth Science, National Oceanography Centre, University of Southampton, Southampton, UK

${ }^{3}$ Earth Sciences Department, Natural History Museum, Cromwell Road, London SW7 5BD, UK

${ }^{4}$ Smurfit Institute of Genetics, Trinity College Dublin, Dublin 2, Ireland 5Zhejiang Museum of Natural History, Hangzhou 310012, People’s Republic of China

${ }^{6}$ Zhejiang Provincial Institute of Archaeology and Cultural Relics, Hangzhou 310014, People’s Republic of China

Correspondence author: Samuel T. Turvey, Institute of Zoology, Zoological Society of London, Regent's Park, London NW1 4RY, UK

(samuel.turvey@ioz.ac.uk)

Short title: Holocene range collapse of giant muntjacs

Word count: 6874 


\section{ABSTRACT}

Aim To clarify the postglacial biogeography of the Annamite and eastern Chinese ungulate faunas, and determine whether current understanding of Asian mammalian biogeography is biased by pseudo-extinctions and pseudoendemism associated with a historical extinction filter.

Location Modern-day specimens of giant muntjac (Muntiacus vuquangensis) from the Annamite Mountains of Laos and Vietnam were compared with zooarchaeological specimens of extinct giant muntjac (M.gigas) from eastern China, and with a reference sample of northern red muntjac (M. vaginalis) from China, Southeast Asia and South Asia.

Methods We analyzed a dataset of antler measurements using MANOVAs, PCAs and scaling relationships, to quantify morphometric variation between extinct and living giant muntjacs in relation to variation shown by a different sympatric large-bodied muntjac species. We also attempted ancient biomolecule analysis of Holocene samples from China.

Results Whereas the combined giant muntjac sample can be differentiated from the reference red muntjac sample in all of our multivariate morphometric analyses, no significant differences are shown between extinct and living giant muntjacs using any analyses, matching the pattern seen when comparing conspecific red muntjac samples from across the same geographic region. 
Main conclusions We find no support for recognizing extinct and living giant muntjacs as distinct taxa, and postglacial populations from China and the Annamites should probably all be referred to M. gigas. The likely conspecificity of giant muntjacs across Eastern and Southeast Asia demonstrates that current-day Asian mammalian biogeography has been shaped by an extinction filter and challenges the idea that the Annamite region represents a cradle of evolution; instead, it may represent a refuge of diversity for some taxa, preserving remnant pseudo-endemic populations of species that have been extirpated across other parts of their former ranges.

\section{Keywords}

endemism, extinction filter, Late Quaternary, mammal extinction, Muntiacus vuquangensis, Neolithic, pseudo-extinction, zooarchaeology 


\section{INTRODUCTION}

Humans have been a dominant driver of patterns in global biodiversity during the Late Quaternary, with anthropogenic activities having substantially affected species diversity and distributions throughout recent millennia as well as during the modern historical period. There is therefore increasing awareness of the need to integrate historical archives into conservation research and environmental management, to provide novel insights into patterns of past extinction and ecosystem structure that are unavailable from short-term ecological studies (Bonebrake et al., 2010; Rick \& Lockwood, 2013; Davies et al., 2014). In particular, due to past human-caused biodiversity loss, observed modern-day geographic ranges of many formerly widespread species represent reduced "pseudo-endemic" distributions lacking a true evolutionary or ecological basis, following extirpation across other parts of a historical range (Steadman, 2006; Turvey, 2009). These remnant subpopulations often persist in peripheral "refugia" that may represent areas of reduced anthropogenic extinction pressure rather than optimal habitat (McShea et al., 1999; Channell \& Lomolino, 2000a, b).

Without an improved understanding of species geographic distributions before disruption by human activity, or subsequent spatiotemporal patterns of human-caused range collapse and their relationship to environmental and anthropogenic parameters, insights into wide-scale biogeographic patterns of species diversity and specific ecological requirements of threatened species will remain incomplete and biased by an "extinction filter" (Balmford, 1996). However, reconstruction of past species ranges is not straightforward, due to major differences in sampling availability and data quality between modern-day ecological studies and fossil, zooarchaeological or historical records (Turvey, 
2009). One source of confusion arises from the increased tendency for palaeontological research to generate taxonomic inflation through overdescription, which has led to some locally extirpated populations of surviving species being erroneously described as distinct, supposedly extinct "species" (see Pregill, 1981 and Steeves et al., 2010 for examples), thus hindering accurate reconstruction of past species ranges and the magnitude of humancaused biodiversity loss through misperception of "pseudo-extinctions".

Developing a robust evidence-base on patterns of past and present human-caused biodiversity loss is of particular significance for Eastern and Southeast Asia. This geographic region today contains the highest levels of threatened land mammal species in the world (Schipper et al., 2008; Sodhi et al., 2010), and is experiencing an ongoing series of range reductions, population extirpations and species extinctions of large-bodied mammals caused by extreme levels of anthropogenic pressure on terrestrial ecosystems (Tilson et al., 2004; Turvey et al., 2007; Brook et al., 2012; Fan et al., 2014). Research into the environmental requirements of threatened Asian mammal species, and ecological correlates of vulnerability or resilience to different human activities in this region, is therefore of substantial conservation importance.

A particular regional hotspot for conservation attention is the Annamite Mountain chain, which extends along the border of Vietnam and Laos and contains some of the last relatively intact moist forests in Indochina (Olson \& Dinerstein, 2002). This ecoregion is famous for the discovery of several previously unknown, regionally endemic and highly threatened mammal species from the 1990s onwards, including the saola (Pseudoryx nghetinhensis), a critically endangered forest bovid (Dung et al., 1993), several muntjacs (Giao et 
al., 1998; Amato et al., 1999), representatives of ancient rodent and lagomorph evolutionary lineages (Surridge et al., 1999; Dawson et al., 2006), and a possible distinct wild pig (Groves et al., 1997; Robins et al., 2006). The first and most distinctive of the recently recognized and geographically localized Annamite muntjacs was the large-antlered or giant muntjac (Muntiacus vuquangensis), the largest extant muntjac, which was described in 1994; this species was originally considered to be so different to other muntjacs, partly on the basis of its unusually large, morphologically distinctive antlers, that it was assigned to the monotypic genus Megamuntiacus before being reassigned to Muntiacus (Tuoc et al., 1994; Schaller \& Vrba, 1996; Timmins et al., 1998). It is classified as Endangered by IUCN (Timmins et al., 2008a). The striking level of modern-day restricted-range endemism observed in the Annamite mammal fauna has been explained by several authors in terms of long-term ecological factors, notably the likely regional persistence of evergreen forests throughout Quaternary glacialinterglacial climatic cycles, with discrete forested areas potentially acting as both environmental refugia and cradles of local speciation in situ (Brandon-Jones, 1996; Schaller \& Vrba, 1996; Giao et al., 1998; Surridge et al., 1999; Sterling \& Hurley, 2005).

However, ecosystems in Eastern and Southeast Asia have been modified by human activity throughout the Late Quaternary. In particular, China's rich Holocene zooarchaeological and fossil records reveal numerous human-caused regional mammal extirpations (e.g. Asian elephant Elephas maximus, giant panda Ailuropoda melanoleuca, Javan rhinoceros Rhinoceros sondaicus, Sumatran rhinoceros Dicerorhinus sumatrensis; Wei et al., 1990; Elvin, 2004; Zhu et al., 2008; Jablonski et al., 2012) and global extinctions of wild populations of locally 
endemic species (e.g. Père David's deer Elaphurus davidianus, short-horned buffalo Bubalus mephistopheles; Cao, 2005; Yang et al., 2008) associated with escalating human overpopulation, natural resource overexploitation and habitat modification throughout recent millennia (Elvin \& Liu, 1998; Elvin, 2004; Ren, 2007). Several mammals that are historically known only from restricted landscapes in Indochina have much broader Quaternary distributions that are likely to have been modified by prehistoric human activity (e.g. kouprey Bos sauveli; Hoffmann, 1986, Bacon et al., 2011), and animal representations on Bronze-Iron Age cultural artefacts have been interpreted as evidence for wider Holocene distribution of saola across Vietnam (Reinicke, 1996). It is therefore possible that modern-day distributions of Annamite mammals represent reduced, refugial pseudo-endemic distributions that are primarily defined by extirpation across other areas of a formerly wider historical range.

Muntjacs are widely represented in the zooarchaeological record of Eastern and Southeast Asia, as they constitute an important target species for hunters (Higham, 2013; Turvey et al., 2015). The Neolithic site of Hemudu (c.7000-6000 BP) in the Yangtze delta region of eastern China contains a large muntjac sample, including a series of distinctive large antlers and associated pedicles, together with incomplete mandible and maxilla fragments, which were described by Wei et al. (1990) as a new extinct species, Muntiacus gigas (Fig. 1). Further large muntjac specimens have since been assigned to M. gigas from Holocene archaeological sites across central and eastern China (Guanzhuangping, Hubei: Eastern Zhou Dynasty, c.2800-2200 BP; Liulinxi, Hubei: Neolithic, c.70006000 BP; Lujiahe, Hubei: Early Shang Dynasty, c.3600-3250 BP; Luoping, Hubei: Late Bronze Age-Han Dynasty, c.2800-1800 BP; Xisiping, Hubei: Neolithic, c.6000 
BP; Tianluoshan, Zhejiang: Neolithic, c.6900-6600 BP), although identification of most specimens is unconfirmed (Fig. 2) (Chen et al., 2004; Wu \& Zhou, 2005; Wu, 2007; Zhang, 2009), and muntjac antlers from a Palaeolithic (Late Pleistocene) site in Yuhang, Zhejiang, are also morphologically similar to specimens of $M$. gigas (lead author, pers. obs.).

Muntiacus gigas and M. vuquangensis appear similar in overall antler morphology and proportions, with antlers in both taxa being very robust in comparison to other muntjacs and bearing prominent longitudinal furrows. The distribution of known records of giant muntjacs in both central-eastern China and Indochina is also comparable to postglacial (zooarchaeological-modern) ranges shown by other muntjac species, including northern red muntjac ( $M$. vaginalis), the other large-bodied mainland Asian muntjac, and black muntjac ( $M$. crinifrons) (Ohtaishi \& Gao, 1990; Rabinowitz et al., 1998; Chen et al., 2004, 2008; Wu, 2007; Groves \& Grubb, 2011), suggesting that significant barriers to gene flow may not have existed between allopatric giant muntjac populations during the Holocene.

However, Muntiacus gigas is almost completely unknown outside the Chinese archaeological literature, was apparently not known to the researchers who described M. vuquangensis, and has never been compared in any detail with extant Annamite giant muntjacs. In order to clarify the status of these two allopatrically distributed giant muntjac taxa, and to assess whether our understanding of regional mammalian biogeography has been affected by misperceptions of pseudo-endemism and pseudo-extinction associated with a historical extinction filter, we conducted quantitative morphometric analyses that include measurement data from modern, historical, and zooarchaeological 
muntjac specimens representing several taxa available in museum collections in Europe and Asia. Our study reveals new insights into the evolutionary history of the Annamite large mammal fauna and into patterns of Holocene range collapse in Asian mammals, with important implications for both biogeography and conservation.

\section{MATERIALS AND METHODS}

We studied 17 modern field-collected specimens of Muntiacus vuquangensis from several localities in Laos in the mammalogy collections of the Natural History Museum, London (NHM) (1994.217, 1994.442-444, 1994.484-486, 1994.491, 1994.493-501), two uncatalogued specimens from Nakai-Nam Theun National Biodiversity Conservation Area, Laos, in the Wildlife Conservation Society's Lao Program office in Vientiane, and one uncatalogued specimen from Vu Quang National Park, Vietnam, on display in the Biological Museum in Vinh University; no giant muntjac specimens were available in the Institute of Ecology and Biological Resources in Hanoi during a visit by the lead author in August 2014. We studied 29 Holocene specimens from the type series of M. gigas in the collections of the Zhejiang Museum of Natural History, Hangzhou (ZMNH) (M10009.1-M10009.29), one Late Pleistocene specimen from Yuhang in the ZMNH collections (M1104), and one Holocene specimen in the collections of the Hemudu Site Museum, Hemudu Town (Hemudu Museum 2926), representing all of the specimens of this taxon that we could find available for study. We also studied a large reference sample of $M$. vaginalis, representing individuals collected from both China and from mainland southern and Southeast Asia north of the Isthmus of Kra (which represents the southern boundary of the range of 
this species as interpreted by Groves \& Grubb, 2011) across a broadly similar distribution to that shown by our giant muntjac sample, and comprising 25 specimens collected from outside China in the mammalogy collections of the NHM (14.12.8.239, 14.6.18.36, 15.12.1.22, 15.12.1.27, 15.5.5.242, 15.5.5.243, 21.5.1.42, 24.9.4.10, 27.2.14.116, 27.2.14.117, 33.4.1.502, 41.199, 50.720, 50.722, $50.725,67.779,76.1883,82.2713,82.2714,85.765,91.8 .7 .47,91.8 .7 .48$, 94.12.19.6, 701.a.a., 2010.488), 22 specimens collected from China in the mammalogy collections of the Institute of Zoology, Beijing $(25035,17917 / 250$, H.754, H.1260, one uncatalogued in Heude collection, one uncatalogued in Sowerby collection, rest uncatalogued), one uncatalogued specimen from Vietnam on display in the Biological Museum in Vinh University, and a hunter trophy in a house in Luc Son village, Pu Mat National Park, Vietnam.

Muntjac antlers show a relatively simple morphology in comparison to antlers of other cervid genera. The following standard series of 14 measurements were taken from complete specimens: (1) beam outer length (above burr); (2) beam outer length (including burr); (3) beam basal circumference; (4) tine outer length (above burr); (5) tine outer length (including burr); (6) tine inner length; (7) tine basal circumference; (8) beamtine tip distance; (9) height of basal angle of antler from base of burr (above orbit); (10) pedicle distal circumference; (11) pedicle distal width; (12) pedicle distal antero-posterior length; (13) pedicle length to frontal-parietal suture; (14) pedicle length to orbit. As many measurements as possible were also taken from incomplete specimens. Measurements were taken using a tape measure and dial callipers accurate to $0.02 \mathrm{~mm}$. For specimens that had associated left and right antlers from the same individual, measurements were only taken from one side 
of the specimen (either the right-hand side in undamaged specimens, or the undamaged side if the specimen showed asymmetrical damage).

Morphometric data were analyzed in R 2.10.1 (R Development Core Team, 2011). Multivariate analyses of variance (MANOVAs) were used to investigate whether quantitative morphometric differences in antler characters could be used to statistically differentiate: (1) available samples of Muntiacus gigas and $M$. vuquangensis; (2) M. vaginalis samples from China versus those from mainland South and Southeast Asia; (3) our combined giant muntjac sample (Muntiacus gigas+vuquangensis) versus our combined M. vaginalis sample. Principal component analysis (PCA) was also conducted to further assess the pattern of morphometric variation shown within and between these three sets of samples. Although all available specimens and measurements were used to calculate descriptive statistics, it was not possible to use the full specimen or measurement series in our MANOVAs or PCAs due to missing data. A series of 17 specimens and 8 measurements (numbers 1, 2, 3, 9, 10, 11, 12, 13) was used for comparison between M.gigas and M. vuquangensis, a series of 44 specimens and 14 measurements was used for comparison between Chinese and non-Chinese samples of M. vaginalis, and a series of 61 specimens and 8 measurements (same as reduced series above) was used in the total combined comparison.

Antler size and morphology varies intraspecifically both in relation to body size and across the lifespan of a deer, and the scaling relationship between different antler proportions can provide a useful taxonomic signal for differentiating between different species (Lister, 1990). The most suitable general index of antler size is the circumference of the pedicle (the beam at the base of the antler) immediately below the burr, which is proportional to both 
body size and age of individual, and which constitutes a standard benchmark measurement against which other antler measurements can be regressed (Lister, 1990). Five measurements (pedicle length to frontal-parietal suture; beam outer length above burr; beam basal circumference; tine outer length above burr; tine basal circumference) were regressed against pedicle distal circumference for our sample series of Muntiacus gigas, M. vuquangensis, and the combined sample of M. vaginalis, with regressions using the maximum number of samples where data for each measurement pair were available. Regression slopes were compared between the three groups, and considered significantly different if confidence intervals of the slopes did not overlap; $83 \%$ confidence intervals were used for comparison because these give an approximate $\alpha=0.05$ test, whereas comparisons using two sets of $95 \%$ confidence intervals are too conservative (Payton et al., 2003). Analyses were performed using the standardized major axis (SMA) calculation from the 'smatr' package in R; SMA analyses are able to summarize the relationship between two variables without necessarily predicting one from the other, and are the most recommended approach when testing for isometry (Warton et al., 2006; Randau et al., 2013).

Ancient biomolecule analysis, including both peptide mass fingerprinting (Zooarchaeology by Mass Spectrometry, "ZooMS”; Buckley et al., 2009) of Type I collagen extracts and ancient DNA extraction, was also carried out on Holocene zooarchaeological samples from Hemudu and Tianluoshan, to investigate the possibility of molecular phylogenetic reconstruction of Muntiacus gigas using the only material available for destructive analysis (see Appendix S1).

\section{RESULTS}


Antler measurements are in general closely comparable between our samples of Muntiacus gigas and M. vuquangensis, although there is some variation in tine dimensions (Table 1). No significant differences are shown in MANOVAs of antler characters either between samples of M. gigas and M. vuquangensis ( $\mathrm{F}=0.535$, $p=0.173$ ), or between $M$. vaginalis samples from China versus those from mainland South and Southeast Asia $(\mathrm{F}=0.924, p=0.546)$. However, statistically significant differentiation is shown in MANOVA between the combined giant muntjac sample versus the combined $M$. vaginalis sample ( $\mathrm{F}=5.104, p<0.001)$. There is similarly no separation of either the two giant muntjac sample series or the two M. vaginalis sample series in PCA, whereas the combined giant muntjac sample and the combined $M$. vaginalis sample show almost total separation along PCA axis 1 (Fig. 3; individual PCAs not shown).

No significant differences are seen in scaling relationships of antler proportions between Muntiacus gigas and M. vuquangensis for any of the measurements regressed against pedicle distal circumference. However, the scaling relationship between pedicle length and pedicle distal circumference differs significantly between $M$. vaginalis and both of our giant muntjac sample series (Table 2, Fig. 4).

Ancient biomolecule analyses through ZooMS resulted in collagen spectra for all four deer samples processed, although taxonomic identification was restricted by both the quality of the spectra and the known limitations of ZooMS within cervids (Buckley \& Collins, 2011). We were nonetheless able to identify artiodactyl peptide markers in all four samples, with one identified as almost certainly cervid. Whilst precise taxonomic identification was not attained, the retrieval of collagen spectra is proof of ancient biomolecule survival from early- 
mid Holocene material from the Yangtze region. In contrast, attempts to amplify mitochondrial DNA were unsuccessful for all samples tested from Hemudu and Tianluoshan, suggesting that whilst collagen persists, ancient DNA from these regions is poorly preserved, similar to the condition in other hot environments (Welker et al., 2015), and preventing us from complementing our morphometric analyses with molecular phylogenetic reconstruction of giant muntjac populations.

\section{DISCUSSION}

Our investigation of the relationships and taxonomic status of giant muntjac populations from Eastern and Southeast Asia provides an important new baseline for understanding the wider postglacial biogeography and evolutionary history of the Asian mammal fauna, and for recognizing the widespread role of extinction filters in generating artefactual patterns of pseudo-extinction and pseudo-endemism in ecoregions with long histories of anthropogenic modification. Unfortunately, it did not prove possible to extract genetic sequence data from $\geq 6000$ year old samples preserved under subtropical environmental conditions. However, whereas it is possible to differentiate our combined giant muntjac sample from our reference sample of red muntjacs using MANOVA, PCA and scaling relationships for available antler measurements, not only do our statistical analyses not differentiate between red muntjac samples from Eastern Asia and Southeast/South Asia, but our available data are also unable to differentiate between specimens assigned to the extinct Muntiacus gigas and the extant $M$. vuquangensis collected from across a similar geographic region. There 
is always the risk of a non-significant result constituting a Type II statistical error in studies of taxa with limited representation in museum collections, when only relatively small sample sizes or measurement series are available for analysis; however, the extensive overlap of specimens assigned to both M. gigas and $M$. vuquangensis along PCA axes 1 and 2 (Fig. 3) indicates that a larger available sample would still be highly unlikely to lead to statistical differentiation of these taxa. Similarly, our study was restricted to the use of morphometric data from antlers, and we encourage further investigation of $M$. gigas material from central and eastern China to test our conclusions; however, even using this relatively restricted dataset we were still able to demonstrate statistically different patterns of morphometric variation between extinct Chinese giant muntjacs, living Annamite giant muntjacs, and a reference sample of sympatric red muntjacs. These morphometric data can therefore be used to inform reassessment of the status of giant muntjac populations in China and the Annamites, and contribute towards more accurate reconstruction of patterns of Asian large mammal ecology, diversity and distribution.

The taxonomy of mainland Asian muntjacs is confusingly complex. Species concepts and species boundaries remain highly contentious, both for some species suggested to occur in both China and Indochina (e.g. M. crinifrons) and for putative species apparently endemic to the Annamite region (e.g. M. puhoatensis, M. putaoensis, M. rooseveltorum, M. truongsonensis), and several taxa are often explicitly treated at the level of species complexes rather than individual species in an attempt to accommodate this uncertainty (Giao et al., 1998; Chen et al., 2008; Timmins et al., 2008b, c; Groves \& Grubb, 2011). More generally, ungulate taxonomy has been greatly affected in recent years by the use 
of alternative species concepts by different authorities, leading to a lack of stability in levels of species diversity recognized in many groups (Groves \& Grubb, 2011; Heller et al., 2013; Zachos et al., 2013). However, despite this uncertainty, our morphometric data can be interpreted within the context of variation seen within and between well-defined muntjac species. Even recent authorities who advocate extensive taxonomic splitting of muntjacs according to a phylogenetic species concept approach (Giao et al., 1998; Groves \& Grubb, 2011) consider that populations of $M$. vaginalis across their mainland range north of the Isthmus of Kra should be interpreted as conspecific. The comparable lack of statistical morphometric differentiation within either our combined $M$. vaginalis sample or our combined giant muntjac sample, in contrast to the significant differentiation observed between these two combined samples, therefore provides no support for recognizing M. gigas and M. vuquangensis as distinct taxa. Instead, giant muntjacs from across China and the Annamites should probably be referred to a single species, with M. gigas Wei et al., 1990 constituting the senior taxonomic synonym of M. vuquangensis (Tuoc et al., 1994), and joining the select group of extant mammal species that were originally described on the basis of Quaternary fossil or zooarchaeological material (e.g. Bulmer's fruit bat Aproteles bulmerae, Chacoan peccary Catagonus wagneri, gray whale Eschrichtius robustus, false killer whale Pseudorca crassidens, bush dog Speothos venaticus; Owen, 1846; Wetzel, 1977; Hyndman \& Menzies, 1980; Bryant, 1995; Beisiegel \& Zuercher, 2005).

Recognizing the likely conspecificity of extinct giant muntjacs from China and extant giant muntjacs in Vietnam and Laos challenges the idea that the pattern of restricted-range endemism seen in the modern-day Annamite 
mammal fauna is necessarily the result of in situ diversification. Instead of a cradle of mammalian evolution, the Annamite region may therefore instead represent a refuge of diversity for some taxa (cf. Mace et al., 2003), preserving remnant pseudo-endemic populations of species that have been extirpated across other parts of their former ranges. Indeed, the pattern of giant muntjac extinction and survival seen across Eastern and Southeast Asia during the Holocene is consistent with established models of the dynamic biogeography of species range change in response to human pressures. The disappearance of giant muntjacs across China and their survival at the south-eastern margin of their known Holocene geographic distribution matches the "range eclipse" or "contagion" model of range collapse, where the biogeography of range contraction is determined by the directional spread of anthropogenic extinction factors, and with final population persistence typically occurring in areas along the edge of a historical range which are impacted last by these extinction forces (Channell \& Lomolino, 2000, 2002; Hemerik et al., 2006). A similar pattern of persistence of remnant populations of declining species in areas experiencing reduced human environmental pressures at the south-western margin of Eastern Asia, following wide-scale extirpation across China in response to documented past regional human population growth and demographic expansion, has recently been demonstrated for gibbons using historical records dating across the late Imperial-modern period (Turvey et al., 2015). Persistence of final populations of giant muntjac in the Annamite Mountain chain up to c.1000 metres above sea level (Timmins et al., 2008a) is also consistent with increased extinction vulnerability of many taxa at lower elevations due to greater human population growth and habitat conversion in these more accessible regions, and 
survival of remnant populations of many threatened species at higher elevations (Li et al., 2002; Fisher, 2011; Zhu et al., 2013; Turvey et al., 2015). Although giant muntjacs have been reported into the first millennium BC in the middle Yangtze region (Wu \& Zhou, 2005; Wu, 2007), the timing of their extirpation across China is somewhat uncertain as material referred to M. gigas from some archaeological sites has not been adequately figured or described; we encourage further research to establish a more robust regional extinction chronology for the species, so that the dynamics and drivers of Asian large mammal range collapse can be better understood.

Habitat preferences of giant muntjac in the Annamite region remain unclear, but the species is considered today to be probably dependent upon dense, wet evergreen and semi-evergreen forest (either closed-canopy forest habitat, or a habitat mosaic including this forest type), and is apparently absent from drier semi-evergreen and deciduous forests (Schaller \& Vrba, 1996; Timmins et al., 1998, 2008a; Rasphone, 2010). In contrast, red muntjac has been recorded from a wide range of wet and dry forests and anthropogenically modified vegetation types in the Annamites (Schaller \& Vrba, 1996; Timmins et al., 1998). The apparent wider environmental tolerance shown by red muntjac may therefore be associated with greater resilience to regional extinction, explaining the different patterns of Holocene population extirpation or persistence displayed by these two formerly sympatric large-bodied muntjac species. However, giant muntjac appears to have formerly occurred in a wider range of habitat types across its former Holocene distribution in China, including subtropical evergreen-deciduous broadleaf forests in the Yangtze delta, a region for which Holocene environments have been reconstructed in some detail (Yi et 
al., 2003; Chen et al., 2005). Further investigation of past habitat associations of giant muntjac in China across the Holocene will help to determine the fundamental niche of this species and its true physiological and ecological limits, in order to help refine appropriate conservation management frameworks and to predict likely responses to future environmental change (cf. Nogués-Bravo, 2009; Veloz et al., 2012).

Our study provides not only a new paradigm for understanding the current status and conservation requirements of the Annamite giant muntjac, but also a new example of how extinction filters can mask historical range collapses, and lead to anthropogenic patterns of pseudo-endemism and pseudoextinction being mistakenly interpreted as ecologically or evolutionarily meaningful biogeographic signals. Our findings therefore contribute to the increasing recognition of anthropogenic extinction filters as a potentially major determinant of observed patterns of current-day mammalian biogeography and extinction risk (Cardillo et al., 2004, 2005; Turvey \& Fritz, 2011), and to the body of literature which demonstrates the importance of long-term Quaternary and historical archives for providing unique new insights to inform current debates on ecology, evolution and conservation (Willis \& Birks, 2006; Lyman, 2012; Crees \& Turvey, 2015). The rich Chinese zooarchaeological record in particular has still been largely unstudied from the perspective of understanding human impacts on wild mammal faunas through time; this important archive has the potential to reconstruct past species distributions and the dynamics and drivers of faunal turnover in Eastern Asia across recent millennia, and to determine the extent to which co-occurring large mammal species exhibit individualistic or fauna-wide extinction filter patterns. It is highly likely that further research into 
this underutilized resource will lead to new advances in our understanding of mammalian biogeography and extinction risk for one of the world's top conservation hotspots.

\section{ACKNOWLEDGEMENTS}

We thank Roberto Portela Miguez and Louise Tomsett (Natural History Museum, London), Jun Chen (Institute of Zoology, Beijing), Wenjie Zheng and Xingsheng Jin (Zhejiang Museum of Natural History, Hangzhou), Bill Robichaud (Wildlife Conservation Society), and Vu Dinh Thong (Institute of Ecology and Biological Resources, Hanoi) for access to collections. We also thank Matthew Collins and Ian Barnes for assistance with biomolecular research, Zhang Ying for assistance in China, Adrian Lister, Darren Naish and Nicholas Wilkinson for useful discussion, and Tim Jeffree and Jessica Bryant for assistance with translation and analysis. Funding was provided by a Royal Society University Research Fellowship (UF080320/UF130573).

\section{REFERENCES}

Amato, G., Egan, M.G., Schaller, G.B., Baker, R.H., Rosenbaum, H.C., Robichaud, W.G. \& DeSalle, R. (1999) Rediscovery of Roosevelt's barking deer (Muntiacus rooseveltorum). Journal of Mammalogy, 80, 639-643.

Bacon, A.-M., Duringer, P., Antoine, P.-O., Demeter, F., Shackelford, L., Sayavongkhamdy, T., Sichanthongtip, P., Khamdalavong, P., Nokhamaomphu, S., Suysuphanh, V., Patole-Edoumba, E., Chabaux, F. \& Pelt, E. (2011) The Middle Pleistocene mammalian fauna from Tam Hang karstic deposit, 
northern Laos: new data and evolutionary hypothesis. Quaternary International, 245, 315-332.

Balmford, A. (1996) Extinction filters and current resilience: the significance for past selection pressures for conservation biology. Trends in Ecology and Evolution, 11, 193-196.

Beisiegel, B.M. \& Zuercher, G.L. (2005) Speothos venaticus. Mammalian Species, 783, 1-6.

Bonebrake, T.C., Christensen, J., Boggs, C.L. \& Ehrlich, P.R. (2010) Population decline assessment, historical baselines, and conservation. Conservation Letters, 3, 371-378.

Brandon-Jones, D. (1996) The Asian Colobinae as indicators of Quaternary climatic change. Biological Journal of the Linnean Society, 59, 327-350.

Brook, S.M., van Coeverden de Groot, P., Scott, C., Boag, P., Long, B., Ley, R.E., Reischer, G.H., Williams, A.C., Mahood, S.P., Hien, T.M., Polet, G., Cox, N. \& Hai, B.T. (2012) Integrated and novel survey methods for rhinoceros populations confirm the extinction of Rhinoceros sondaicus annamiticus from Vietnam. Biological Conservation, 155, 59-67.

Bryant, P.J. (1995) Dating remains of gray whales from the eastern North Atlantic. Journal of Mammalogy, 76, 857-861.

Buckley, M. \& Collins, M.J. (2011) Collagen survival and its use for species identification in Holocene-lower Pleistocene bone fragments from British archaeological and paleontological sites. Antiqua, 1, 1-7.

Buckley, M., Collins, M.J., Thomas-Oates, J. \& Wilson, J. (2009) Species identification by analysis of bone collagen using matrix-assisted laser 
desorption/ionisation time-of-flight mass spectrometry. Rapid Communications in Mass Spectrometry, 23, 3843-3854.

Cao, K. (2005) Research on the mi-deer. Shanghai Scientific Education Publishing House, Shanghai.

Cardillo, M., Mace, G.M., Jones, K.E., Bielby, J., Bininda-Emonds, O.R.P., Sechrest, W., Orme, C.D.L. \& Purvis, A. (2005) Multiple causes of high extinction risk in large mammal species. Science, 309, 1239-1241.

Cardillo, M., Purvis, A., Sechrest, W., Gittleman, J.L., Bielby, J. \& Mace, G.M. (2004) Human population density and extinction risk in the world's carnivores. PLoS Biology, 2, 909-914.

Channell, R. \& Lomolino, M.V. (2000) Dynamic biogeography and conservation of endangered species. Nature, 403, 84-86.

Channell, R. \& Lomolino, M.V. (2002) Trajectories to extinction: spatial dynamics of the contraction of geographical ranges. Journal of Biogeography, 27, 169179.

Chen, Q., Wang, S. \& Zhang, D. (2004) Research on ancient animal remains from the Qingjiang River basin. Scientific Publishing House, Beijing.

Chen, Z., Wang, Z., Schneiderman, J., Tao, J. \& Cai, Y. (2005) Holocene climate fluctuations in the Yangtze delta of eastern China and the Neolithic response. Holocene, 15, 915-924.

Chen, M., Guo, G., Wu, P. \& Zhang, E. (2008) Identification of black muntjac (Muntiacus crinifrons) in Tibet, China, by cytochrome $b$ analysis. Conservation Genetics, 9, 1287-1291.

Crees, J.J. \& Turvey, S.T. (2015) What constitutes a 'native' species? Insights from the Quaternary faunal record. Biological Conservation, 186, 143-148. 
Davies, A.L., Colombo, S. \& Hanley, N. (2014) Improving the application of longterm ecology in conservation and land management. Journal of Applied Ecology, 51, 53-70.

Dawson, M.R., Marivaux, L., Li, C.-K., Beard, C. \& Métais, G. (2006) Laonastes and the "Lazarus effect" in recent mammals. Science, 311, 1456-1458.

Dung, V.V., Giao, P.M., Chinh, N.N., Tuoc, D., Arctander, P. \& MacKinnon, J. (1993) A new species of living bovid from Vietnam. Nature, 363, 443-445.

Elvin, M. (2004). The retreat of the elephants: an environmental history of China. Yale University Press, New Haven.

Elvin, M. \& Liu, T. (Eds) (1998) Sediments of time: environment and society in Chinese history. Cambridge University Press, Cambridge.

Fan, P., Fei, H. \& Luo, A. (2014) Ecological extinction of the Critically Endangered northern white-cheeked gibbon Nomascus leucogenys in China. Oryx, 48, 5255.

Fisher, D.O. (2011) Trajectories from extinction: where are missing mammals rediscovered? Global Ecology and Biogeography, 20, 415-425.

Giao, P.M., Tuoc, D., Dung, V.V., Wikramanayake, E.D., Amato, G., Arctander, P. \& MacKinnon, J.R. (1998) Description of Muntiacus truongsonensis, a new species of muntjac (Artiodactyla: Muntiacidae) from central Vietnam, and implications for conservation. Animal Conservation, 1, 61-68.

Groves, C., Schaller, G.B., Amato, G. \& Khounboline, K. (1997) Rediscovery of the wild pig Sus bucculentus. Nature, 386, 335.

Groves, C. \& Grubb, P. (2011) Ungulate taxonomy. Johns Hopkins University Press, Baltimore. 
Heller, R., Frandsen, P., Lorenzen, E.D. \& Siegismund, H.R. (2013) Are there really twice as many bovid species as we thought? Systematic Biology, 62, 490-493.

Hemerik, L., Hengeveld, R. \& Lippe, E. (2006) The eclipse of species ranges. Acta Biotheoretica, 54, 255-266.

Higham, C. (2013) Hunter-gatherers in southeast Asia: from prehistory to the present. Human Biology, 85, 21-43.

Hoffmann, R.S. (1986) A new locality record for the kouprey from Viet Nam, and an archaeological record from China. Mammalia, 50, 391-395.

Hyndman, D. \& Menzies, J.I. (1980) Aproteles bulmerae (Chiroptera:

Pteropodidae) of New Guinea is not extinct. Journal of Mammalogy, 61, 159160.

Jablonski, N.G., Ji, X., Liu, H., Li, Z., Flynn, L.J. \& Li, Z. (2012) Remains of Holocene giant pandas from Jiangdong Mountain (Yunnan, China) and their relevance to the evolution of quaternary environments in south-western China. Historical Biology, 24, 527-536.

Li, B., Pan, R. \& Oxnard, C. (2002) Extinction of snub-nosed monkeys in China during the past 400 years. International Journal of Primatology, 23, 1227-1244.

Lister, A. (1990) Critical reappraisal of the Middle Pleistocene deer species “Cervus" elaphoides Kahlke. Quaternaire, 3-4, 175-192.

Liu, L. \& Chen, X. (2012) The archaeology of China: from the Late Paleolithic to the early Bronze Age. Cambridge University Press, Cambridge.

Lyman, R.L. (2012) A warrant for applied palaeozoology. Biological Reviews, 87, 513-525.

Mace, G.M., Gittleman, J.J. \& Purvis, A. (2003) Preserving the Tree of Life. Science, 300, 1707-1709. 
McShea, W.J., Leimbruger, P., Aung, M., Monfort, S.L. \& Wemmer, C. (1999) Range collapse of a tropical cervid (Cervus eldi) and the extent of remaining habitat in central Myanmar. Animal Conservation, 2, 173-183.

Nogués-Bravo, D. (2009) Predicting the past distribution of species climatic niches. Global Ecology and Biogeography, 18, 521-531.

Ohtaishi, N. \& Gao, Y.T. (1990) A review of the distribution of all species of deer (Tragulidae, Moschidae and Cervidae) in China. Mammal Review, 20, 125-144.

Olson, D.M. \& Dinerstein, E. (2002) The Global 200: priority ecoregions for global conservation. Annals of the Missouri Botanical Garden, 89, 199-224.

Owen, R. (1846) A history of British fossil mammals, and birds. John Van Voorst, London.

Payton, M.E., Greenstone, M.H. \& Schrenker, N. (2003) Overlapping confidence intervals or standard error intervals: what do they mean in terms of statistical significance? The Journal of Insect Science, 3, 34.

Pregill, G. (1981) Late Pleistocene herpetofaunas from Puerto Rico. University of Kansas Museum of Natural History, Miscellaneous Publications, 71, 1-72.

Randau, M., Carbone, C. \& Turvey, S.T. (2013) Canine evolution in sabretoothed carnivores: natural selection or sexual selection? PLoS ONE, 8(8), e72868.

R Development Core Team (2011) R: a language and environment for statistical computing. R Foundation for Statistical Computing, Vienna.

Rabinowitz, A., Amato, G. \& Khaing, S.T. (1998) Discovery of the black muntjac, Muntiacus crinifrons (Artiodactyla, Cervidae), in north Myanmar. Mammalia, 62, 105-108.

Rasphone, A. (2010) Investigating the spatial distribution of large-antlered muntjac in central Lao PDR. Master's thesis, Australian National University. 
Reinicke, A. (1996) Bi-cephalous animal-shaped ear pendants in Vietnam. Bead Study Trust Newsletter, 28, 5-7.

Ren, G. (2007) Changes in forest cover in China during the Holocene. Vegetation History and Archaeobotany, 16, 119-126.

Rick, T.C. \& Lockwood, R. (2013) Integrating paleobiology, archaeology, and history to inform biological conservation. Conservation Biology, 27, 45-54.

Robins, J.H., Ross, H.A., Allen, M.S. \& Matisoo-Smith, E. (2006.) Taxonomy: Sus bucculentus revisited. Nature, 440, E7.

Schaller, G.B. \& Vrba, E.S. (1996) Description of the giant muntjac (Megamuntiacus vuquangensis) in Laos. Journal of Mammalogy, 77, 675-683.

Schipper, J., et al. (2008) The status of the world's land and marine mammals: diversity, threat, and knowledge. Science, 322, 225-230.

Sodhi, N.S., Posa, M.R.C., Lee, T.M., Bickford, D., Koh, L.P. \& Brook, B.W. (2010) The state and conservation of southeast Asian biodiversity. Biodiversity and Conservation, 19, 317-328.

Steadman, D.W. (2006) An extinct species of tooth-billed pigeon (Didunculus) from the Kingdom of Tonga, and the concept of endemism in insular landbirds. Journal of Zoology, 268, 233-241.

Steeves, T.E., Holdaway, R.N., Hale, M.L., McLay, E., McAllan, I.A.W., Christian, M., Hauber, M.E. \& Bunce, M. (2009) Merging ancient and modern DNA: extinct seabird taxon rediscovered in the North Tasman Sea. Biology Letters, 6, 94-97.

Sterling, E.J. \& Hurley, M.M. (2005) Conserving biodiversity in Vietnam: applying biogeography to conservation research. Proceedings of the California Academy of Sciences, 56 (Suppl. 1), 98-118. 
Surridge, A.K., Timmins, R.J., Hewitt, G.M. \& Bell, D.J. (1999) Striped rabbits in southeast Asia. Nature, 400, 726.

Tilson, R., Hu, D., Muntifering, J. \& Nyhus, P.J. (2004) Dramatic decline of wild South China tigers Panthera tigris amoyensis: field survey of priority tiger reserves. Oryx, 38, 40-47.

Timmins, R.J., Evans, T.D., Khounboline, K. \& Sisomphone, C. (1998) Status and conservation of the giant muntjac Megamuntiacus vuquangensis, and notes on other muntjac species in Laos. Oryx, 32, 59-67.

Timmins, R.J., Duckworth, J.W. \& Long, B. (2008a) Muntiacus vuquangensis. IUCN Red List of Threatened Species, Version 2014.3. Accessible at <www.iucnredlist.org > Downloaded on 17 April 2015.

Timmins, R.J., Duckworth, J.W. \& Long, B. (2008b) Muntiacus rooseveltorum. IUCN Red List of Threatened Species, Version 2014.3. Accessible at <www.iucnredlist.org> Downloaded on 17 April 2015.

Timmins, R.J., Duckworth, J.W. \& Long, B. (2008c) Muntiacus truongsonensis. IUCN Red List of Threatened Species, Version 2014.3. Accessible at <www.iucnredlist.org> Downloaded on 17 April 2015.

Tuoc, D., Dung, V.V., Dawson, S., Arctander, P. \& MacKinnon, J. (1994) Introduction of a new large mammal species in Vietnam. Science and Technology News, Forest Inventory and Planning Institute (Hanoi), March, 4-13 (in Vietnamese).

Turvey, S.T. (2009) Holocene extinctions. Oxford University Press, Oxford. Turvey, S.T., Crees, J.J. \& Di Fonzo, M.M.I. (2015) Historical data as a baseline for conservation: reconstructing long-term faunal extinction dynamics in Late Imperial-modern China. Proceedings of the Royal Society B, 282, 20151299. 
Turvey, S.T. \& Fritz, S.A. (2011) The ghosts of mammals past: biological and geographical patterns of global mammalian extinction across the Holocene. Philosophical Transactions of the Royal Society B, 366, 2564-2576.

Turvey, S.T., Pitman, R.L., Taylor, B.L., Barlow, J., Akamatsu, T., Barrett, L.A., Zhao, X., Reeves, R.R., Stewart, B.S., Pusser, L.T., Wang, K., Wei, Z., Zhang, X., Richlen, M., Brandon, J.R. \& Wang, D. (2007) First human-caused extinction of a cetacean species? Biology Letters, 3, 537-540.

Turvey, S.T., Trung, C.T., Quyet, V.D., Nhu, H.V., Thoai, D.V., Tuan, V.C.A., Hoa, D.T., Kacha, K., Sysomphone, T., Wallate, S., Hai, C.T.T., Thanh, N.V. \& Wilkinson, N.M. (2015) Interview-based sighting histories can inform regional conservation prioritization for highly threatened cryptic species. Journal of Applied Ecology, 52, 422-433.

Veloz, S.D., Williams, J.W., Blois, J.L., He, F., Otto-Bliesner, B. \& Liu, Z. (2012) Nonanalog climates and shifting realized niches during the Late Quaternary: implications for 21st-century predictions by species distribution models. Global Change Biology, 18, 1698-1713.

Warton, D.I., Wright, I.J., Falster, D.S. \& Westoby, M. (2006) Bivariate line-fitting methods of allometry. Biological Reviews, 81, 259-291.

Wei, F., Wu, W., Zhang, M. \& Han, D. (1990) The fauna from the Neolithic site at Hemudu, Zhejiang. Haiyang Press, Beijing.

Welker, F., Collins, M.J., Thomas, J.A., Wadsley, M., Brace, S., Cappellini, E., Turvey, S.T., Reguero, M., Gelfo, J.N., Kramarz, A., Burger, J., Thomas-Oates, J., Ashford, D.A., Ashton, P., Rowsell, K., Porter, D.M., Kessler, B., Fisher, R., Baessmann, C., Kaspar, S., Olsen, J., Kiley, P., Elliott, J.A., Kelstrup, C., Mullin, V., Hofreiter, M., Willerslev, E., Hublin, J.J., Orlando, L., Barnes, I. \& MacPhee R.D.E. 2015. 
Ancient proteins resolve the evolutionary history of Darwin's South American ungulates. Nature, 522, 81-84.

Wetzel, R.M. (1977) The extinction of peccaries and a new case of survival. Annals of the New York Academy of Sciences, 288, 538-544.

Willis, K.J. \& Birks, H.J.B. (2006) What is natural? The need for a long-term perspective in biodiversity conservation. Science, 314, 1261-1265.

Wu, X. (2007) Three Gorges: zooarchaeology. Chongqing Press, Chongqing.

Wu, X. \& Zhou, G. (2005) The animal's remains from Guanzhuangping site in Hubei. Acta Anthropologica Sinica, 24, 232-248.

Yang, D., Liu, L., Chen, X. \& Speller, C.F. (2008) Wild or domesticated: DNA analysis of ancient water buffalo remains from north China. Journal of Archaeological Science, 35, 2778-2785.

Yi, S., Saito, Y., Zhao, Q. \& Wang, P. (2003) Vegetation and climate changes in the Changjiang (Yangtze River) Delta, China, during the past 13,000 years inferred from pollen records. Quaternary Science Reviews, 22, 1501-1519.

Zachos, F.E., Apollonio, M., Bärmann, E.V., Festa-Bianchet, M., Gölich, U., Habel, J.C., Haring, E., Kruckenhauser, L., Lovari, S., McDevitt, A.D., Pertoldi, C., Rössner, G.E., Sánchez-Villagra, M.R., Scandura, M. \& Suchentrunk, F. (2013) Species inflation and taxonomic artefacts: a critical comment on recent trends in mammalian classification. Mammalian Biology, 78, 1-6.

Zhang, Y. (2009) Issues of the faunal remains at Tianluoshan, Jiangjiasha and Bianjiashan. Master's thesis, School of Archaeology and Museology, Peking University.

Zhu, C., Ma, C., Ouyang, J., Li, Z., Yin, Q., Sun, Z., Huang, Y., Flad, R.K., Li, L. \& Li, Y. (2008) Animal diversities and characteristics of environmental change 
revealed by skeletons unearthed at Zhongba Site of Chongqing City, China. Chinese Science Bulletin, 53 (Suppl. 1), 74-86.

Zhu, L., Hu, Y., Zhang, Z. \& Wei, F. (2013) Effect of China's rapid development on its iconic giant panda. Chinese Science Bulletin, 58, 2134-2139. 


\section{Supporting Information}

Additional supporting information may be found in the online version of this article:

Appendix S1 Ancient biomolecule analysis methods.

\section{Biosketch}

Samuel Turvey is a conservation biologist interested in the use of the Quaternary fossil record and other long-term baselines to inform current-day management of threatened species. His research focuses on highly threatened species and ecosystems in Eastern and Southeast Asia.

Author contributions: S.T.T. conceived the ideas; S.T.T., S.G. and G.S.

collected/provided the data; J.H., S.B., V.M. and S.T.T. analyzed the data; and S.T.T. led the writing.

Handling editor: Lawrence Heaney 
Table 1. Antler measurements for our sample series of Muntiacus gigas and $M$. vuquangensis, showing mean value in $\mathrm{mm}$, with $\mathrm{SD}$ and sample size in parentheses, for each measurement.

\begin{tabular}{|l|c|c|}
\hline Measurement & Muntiacus gigas & Muntiacus vuquangensis \\
\hline Beam outer length (above burr) & $165.8(24.6,19)$ & $186.7(45.2,19)$ \\
\hline Beam outer length (incl. burr) & $170.4(24.9,19)$ & $196.9(56.2,19)$ \\
\hline Beam basal circumference & $76.0(12.6,28)$ & $75.2(15.9,20)$ \\
\hline Tine outer length (above burr) & $43.5(16.4,14)$ & $72.2(26.6,20)$ \\
\hline Tine outer length (incl. burr) & $48.3(16.1,14)$ & $78.5(27.0,20)$ \\
\hline Tine inner length & $34.1(12.6,14)$ & $53.9(17.0,20)$ \\
\hline Tine basal circumference & $46.8(10.9,22)$ & $58.4(25.9,20)$ \\
\hline Beam-tine tip distance & $116.2(19.3,7)$ & $115.4(27.4,19)$ \\
\hline $\begin{array}{l}\text { Height of basal angle of antler from base } \\
\text { of burr (above orbit) }\end{array}$ & $23.3(5.4,26)$ & $23.9(5.1,20)$ \\
\hline Pedicle distal circumference & $75.2(7.9,17)$ & $85.5(13.0,10)$ \\
\hline Pedicle distal width & $19.0(2.5,17)$ & $21.7(2.3,12)$ \\
\hline Pedicle distal antero-posterior length & $27.7(3.2,17)$ & $31.3(5.3,12)$ \\
\hline Pedicle length to frontal-parietal suture & $55.5(9.9,16)$ & $55.9(8.9,19)$ \\
\hline Pedicle length to orbit & $94.3(11.1,13)$ & $108.0(10.8,19)$ \\
\hline
\end{tabular}


Table 2. Upper and lower bounds of 83\% confidence intervals for regressions of different measurements against pedicle distal circumference for samples of Muntiacus gigas, M. vuquangensis and M. vaginalis. Asterisk indicates that the slope of $M$. vaginalis is significantly different to the slopes of the two giant muntjac taxa.

\begin{tabular}{|l|l|l|l|l|l|l|}
\hline Measurement & \multicolumn{2}{|l|}{ Muntiacus gigas } & \multicolumn{2}{l|}{ Muntiacus vuquangensis } & \multicolumn{2}{l|}{ Muntiacus vaginalis } \\
\hline & $\begin{array}{l}\text { Lower bound } \\
(8.5 \%)\end{array}$ & $\begin{array}{l}\text { Upper bound } \\
(91.5 \%)\end{array}$ & $\begin{array}{l}\text { Lower bound } \\
(8.5 \%)\end{array}$ & $\begin{array}{l}\text { Upper bound } \\
(91.5 \%)\end{array}$ & $\begin{array}{l}\text { Lower bound } \\
(8.5 \%)\end{array}$ & $\begin{array}{l}\text { Upper bound } \\
(91.5 \%)\end{array}$ \\
\hline Pedicle length * & -1.779 & -0.903 & -1.284 & -0.593 & -2.946 & -1.975 \\
\hline Beam length & 2.591 & 6.980 & 2.654 & 4.862 & 4.074 & 5.628 \\
\hline Beam circumference & 1.332 & 2.603 & 1.068 & 1.854 & 1.455 & 1.963 \\
\hline Tine length & 2.003 & 5.930 & 1.264 & 2.547 & 1.819 & 2.608 \\
\hline Tine circumference & 1.152 & 2.230 & 1.205 & 2.266 & 1.417 & 2.066 \\
\hline
\end{tabular}


Figure 1. Antlers of Muntiacus gigas from the Neolithic archaeological site of Hemudu, Yuyao County, Zhejiang Province, China. (a) ZMNH M10009.2. (b) ZMNH M10009.22. Scale bar=2cm.

Figure 2. Map of China and mainland Southeast Asia, showing modern-day distribution of Muntiacus vuquangensis (grey) from Timmins et al. (2008a), and Holocene zooarchaeological records of M. gigas (triangles). Key: 1, Guanzhuangping; 2, Liulinxi; 3, Xisiping; 4, Luoping; 5, Lujiahe; 6, Yuhang; 7, Tianluoshan; 8, Hemudu.

Figure 3. Principal component analysis for antler and pedicle measurements of Muntiacus gigas (filled circles), M. vuquangensis (filled triangles), M. vaginalis specimens from China (open circles), and M. vaginalis specimens from mainland South and Southeast Asia (open triangles). Axis 1: percentage variance $=76.21 \%$, eigenvalue=6.10. Axis 2: percentage variance $=9.92 \%$, eigenvalue $=1.20$.

Figure 4. Regressions of pedicle length against pedicle distal circumference for (a) Muntiacus gigas $\left(\mathrm{r}^{2}=0.200, \mathrm{p}=0.082\right)$, (b) M. vuquangensis $\left(\mathrm{r}^{2}=0.448, \mathrm{p}=0.034\right)$, and (c) combined sample of $M$. vaginalis $\left(\mathrm{r}^{2}=0.061, \mathrm{p}=0.094\right)$. 